\title{
Pronuclear Migration and Cytoskeletal Organization of Porcine Oocytes Activated by Various Stimuli
}

\author{
Hiroyuki Suzuki ${ }^{1 *}$, Noriko Kagawa ${ }^{1}$ and Koji Toyokawa ${ }^{1}$ \\ ${ }^{1}$ Faculty of Agriculture and Life Sciences, Hirosaki University, Hirosaki 036-8561, Japan
}

\begin{abstract}
A variety of physical and chemical stimuli initiate egg activation events. This study was designed to investigate the rates of pronuclear formation and the cytoskeletal organization of porcine oocytes activated by various stimuli. Oocytes matured for 44-60 hrs were activated by one of the following treatments: double electric pulses (EP, $150 \mathrm{~V} / \mathrm{mm}$ for $60 \mu \mathrm{sec}, 1 \mathrm{sec}$ apart), ethanol (7\% for $5 \mathrm{~min}$ ), calcium ionophore A23187 (CaA, $50 \mu \mathrm{M}$ for $2 \mathrm{~min}$ ), cycloheximide ( $\mathrm{CHX}, 5 \mu \mathrm{g} / \mathrm{ml}$ for $6 \mathrm{hrs}$ ), or 6-dimethylaminopurine (DMAP, $2.5 \mathrm{mM}$ for $4 \mathrm{hrs}$ ). EP yielded the highest activation rate (97\%). CaA and DMAP activated the oocytes in relatively higher proportions than did ethanol and $\mathrm{CHX}$ (74 and $83 \%$ vs. 55 and $41 \%$, respectively). After $\mathrm{CHX}$ and DMAP treatments, egg fragmentation was significantly increased (65 and $82 \%$, respectively) and the polar body emission was restrained. After activation with EP, ethanol or $\mathrm{CaA}$, the pronucleated oocytes possessed a microtubule-rich domain around the pronucleus, which was concomitantly surrounded by microfilaments. In oocytes activated with $\mathrm{CHX}$ or DMAP, however, microtubules and microfilaments did not synchronously form a concentrated domain. We suggest that activation with a protein synthesis/phosphorylation inhibitor may have affects on distribution and function of the cytoskeleton of the oocyte different from those elicited by treatments with $E P$, ethanol or $\mathrm{CaA}$, which result in higher proportions of eggs with the pronucleus restrained in the peripheral ooplasm and greater egg fragmentation. Key words: Pig oocyte, Activation, Cytoskeleton, Fragmentation
\end{abstract}

Mammalian oocytes arrest at metaphase of the second meiosis (MII) until fertilization or parthenogenetic

Received: June 12, 2002

Accepted: August 23, 2002

*To whom correspondence should be addressed.

e-mail: suzuki@cc.hirosaki-u.ac.jp activation occurs. The activation stimulus at fertilization induces calcium oscillation in the oocytes [1]. Various treatments elevating intracellular calcium levels $\left(\left[\mathrm{Ca}^{2+}\right]_{i}\right)$, e.g., ethanol [2], calcium ionophore A23187 (CaA) [3, 4], or electric pulses (EP) [4-7], are used for artificial activation of oocytes in mammals, including pigs. Maintenance of the MII arrest is dependent on the maintenance of high activities of maturation/M-phase promoting factor (MPF) [8]. Protein synthesis inhibitors, cycloheximide $(\mathrm{CHX})$, puromycin and $\mathrm{H} 7$ [1-(5isoquinolinesulfonyl)-2-methipiperazine, $\mathrm{HCL}$, or protein phosphorylation inhibitor, 6-dimethylaminopurine (6DMAP), can induce or accelerate the pronuclear formation of oocytes in mice [9, 10], cattle [11] and pigs [12-14]. Moreover, an age-dependent response of the oocyte to activation stimulation is recognized in mice and cattle, among which aged oocytes can be more easily activated than young oocytes [15-19]. Our previous study showed that pig oocytes are effectively activated with double EP regardless of oocyte aging and cytoskeletal organization is involved in the dynamic events during normal oocyte maturation and activation $[20,21]$. However, the relationship between these morphological changes and the underlying biochemical events are still poorly understood and little information is available on the dynamic changes of the cytoskeleton of parthenogenotes stimulated by different kinds of stimuli in the pig. The objectives of the present study were to investigate the cytoskeletal organization and types of pronuclear formation in the pig oocytes treated with different kinds of activators: namely, the stimuli elevating $\left[\mathrm{Ca}^{2+}\right]_{i}$, e.g., EP, ethanol and $\mathrm{CaA}$, the inhibitor of protein synthesis $\mathrm{CHX}$, and the inhibitor of protein phosphorylation DMAP. This study will provide a basis for understanding the mechanism whereby the way of activation is associated with the organization of microtubules and microfilaments of the oocytes during pronuclear formation. 


\section{Materials and Methods}

\section{Maturation and aging of oocytes}

Oocytes were aspirated from antral follicles $(2-5 \mathrm{~mm}$ in diameter) of ovaries collected from slaughtered prepubertal gilts. After being washed with Dulbecco's phosphate buffered saline containing $0.1 \%$ polyvinyl alcohol, groups of 10-15 oocytes were transferred to NCSU23 medium supplemented with $10 \%(\mathrm{v} / \mathrm{v})$ porcine follicular fluid, 10 i.u./ml eCG (Teikoku Hormone Mfg. Co. Ltd., Tokyo, Japan) and 10 i.u./ml hCG (Mochida Pharmaceutical Co. Ltd., Tokyo, Japan). The oocytes were cultured for $24 \mathrm{hrs}$, and then incubated in NCSU23 without hormones for a total period of 44,50 or $60 \mathrm{hrs}$ at $39^{\circ} \mathrm{C}$ in $5 \% \mathrm{CO}_{2}$ in air. This culture system allowed about $90 \%$ maturation of oocytes $[22,23]$.

\section{Activation of oocytes}

At the end of culture, oocytes were denuded of cumulus cells in NCSU23 supplemented with $0.1 \%$ hyaluronidase. Oocytes exhibiting the first polar body $(\mathrm{PBI})$ were allocated to one of the following treatments: 1) stimulation with double EP $(150 \mathrm{~V} / \mathrm{mm}$ for $60 \mu \mathrm{sec}, 1$ sec apart) $[20,21]$, 2) $100-\mu$ l droplets of NCSU23 containing $7 \%$ ethanol for $5 \mathrm{~min}, 3) 100-\mu$ droplets of BSA-free NCSU23 containing $50 \mu \mathrm{M}$ CaA (Sigma, St Louis, MO, USA) for $2 \mathrm{~min}, 4) 100-\mu$ droplets of NCSU23 containing $5 \mu \mathrm{g} / \mathrm{ml}$ cycloheximide (Sigma Chemical Co., MO, USA) for 6 hrs, or 5) 2.5 mM 6dimetylaminopurine (Sigma) for $4 \mathrm{hrs}$. Incubation in NCSU23 droplets without chemicals served as a control. After various stimuli, oocytes were washed and placed in 100- $\mu$ l droplets of NCSU23 supplemented with $0.4 \% \mathrm{BSA}$ under mineral oil at $39^{\circ} \mathrm{C}$ in $5 \% \mathrm{CO}_{2}$ in air. Twelve hours after initiation of activation, the oocytes were processed for fluorescence staining to assess the pronuclear formation and the cytoskeletal distribution.

\section{Fluorescence observations}

Methods for preparing samples for fluorescence observations have been reported previously [22]. Briefly, the oocytes were fixed in a microtubule stabilization buffer at $37^{\circ} \mathrm{C}$ for $1 \mathrm{hr}$, washed extensively and blocked overnight at $4^{\circ} \mathrm{C}$ in the washing medium. Afterwards, the fixed samples were exposed to monoclonal anti- $\beta$ tubulin mouse antibodies (1:200; Sigma T-4026) at $4^{\circ} \mathrm{C}$ overnight, washed, and then incubated with fluorescein isothiocyanate (FITC)conjugated goat anti-mouse IgG antibody (1:200; Sigma $\mathrm{F}-0257)$ at $37^{\circ} \mathrm{C}$ for $2 \mathrm{hrs}$. After rinsing, the samples were stained with rhodamine-phalloidin (1:1000;
Molecular Probes, Eugene, OR, USA) for microfilaments for $1 \mathrm{hr}$, washed again, then stained for DNA with Hoechst $33342(10 \mu \mathrm{g} / \mathrm{ml})$ in mounting medium containing PBS and glycerol (1:1), and finally mounted onto slides.

The samples were viewed under an Olympus microscope (BX-FLA, Olympus, Tokyo, Japan). For FITC a filtered U-MWIB set was utilized, a U-WIB set was used for rhodamine and a U-MWU set for Hoechst. A cooled CCD video system (ImagePoint, Photometrics Ltd., Tucson, AZ, USA) was used to obtain images on a computer and color adjustment was performed by IPLab-Spectrum $P$ software (Signal Analytics Corporation, Vienna, VA, USA).

\section{Statistical analysis}

Three replicate trials were conducted for each treatment. Data were assessed by analysis of variance with the help of the BMDP program (BMDP Statistical Software, Inc., Los Angeles, CA, USA). When appropriate, percentage data were arcsine transformed. Differences between the means were determined using Tukey's multiple range test. Data were represented as the mean \pm s.e.m. and the level of statistical significance was taken as $\mathrm{P}<0.05$.

\section{Results}

\section{Rates and types of pronuclear formation}

There was no evidence of spontaneous activation after culture up to $72 \mathrm{hrs}$. Activation rates of pig oocytes treated by different stimuli are summarized in Table 1. The highest incidence of activation was obtained in electrostimulated oocytes with an overall mean of $97 \%$. When treated with EP, ethanol and DMAP, oocytes at different maturational ages showed no significant differences in activation rates. In contrast, when oocytes were treated with $\mathrm{CaA}$ and $\mathrm{CHX}$, the activation rates were significantly higher in aged oocytes than in young ones. Incidence of egg fragmentation increased significantly after $\mathrm{CHX}$ and DMAP treatments (65 and $82 \%$, respectively) compared to the other treatments (23-34\%), although the eggs were pronucleated.

Types of pronuclear formation were very different among the treatments employed (Table 2). Oocytes with one pronucleus and two polar bodies (PBI and $P B I I)$ were found as the predominant pattern in the EP, ethanol and $\mathrm{CaA}$ groups. In contrast, the frequency of the PBII emission diminished after $\mathrm{CHX}$ and DMAP treatments. About $90 \%$ of activated oocytes $(n=177)$ in 
Table 1. Activation rates of pig oocytes of different maturational age treated by different stimuli

\begin{tabular}{|c|c|c|c|c|c|c|}
\hline \multirow{2}{*}{ Treatment* } & \multirow{2}{*}{$\begin{array}{c}\text { Age of } \\
\text { oocytes } \\
\text { (h) }\end{array}$} & \multirow{2}{*}{$\begin{array}{c}\text { No. of } \\
\text { oocytes } \\
\text { examined }\end{array}$} & \multirow{2}{*}{$\begin{array}{c}\text { Mean \% of } \\
\text { oocytes } \\
\text { activated }\end{array}$} & \multicolumn{3}{|c|}{$\begin{array}{l}\text { Mean } \% \text { of activated } \\
\text { oocytes showing** }\end{array}$} \\
\hline & & & & PN & PN-Frag & MIII \\
\hline \multirow[t]{4}{*}{ EP } & 44 & 62 & 93 & 66 & 34 & 0 \\
\hline & 50 & 64 & 98 & 76 & 24 & 0 \\
\hline & 60 & 73 & 100 & 64 & 33 & 3 \\
\hline & Overall mean & & $97 \pm 1^{\mathrm{A}}$ & $67 \pm 4^{\mathrm{A}}$ & $31 \pm 4^{\mathrm{B}}$ & $1 \pm 1$ \\
\hline \multirow[t]{4}{*}{ ETOH } & 44 & 66 & 48 & 56 & 25 & 19 \\
\hline & 50 & 69 & 49 & 68 & 32 & 0 \\
\hline & 60 & 92 & 68 & 51 & 46 & 3 \\
\hline & Overall mean & & $55 \pm 7^{\mathrm{C}}$ & $58 \pm 6^{\mathrm{A}}$ & $34 \pm 5^{\mathrm{B}}$ & $7 \pm 5$ \\
\hline \multirow[t]{4}{*}{$\mathrm{CaA}$} & 44 & 99 & $52^{\mathrm{b}}$ & 81 & 11 & 8 \\
\hline & 50 & 94 & $88^{\mathrm{a}}$ & 79 & 21 & 0 \\
\hline & 60 & 97 & $82^{\mathrm{a}}$ & 59 & 38 & 3 \\
\hline & Overall mean & & $74 \pm 6^{\mathrm{B}}$ & $73 \pm 5^{\mathrm{A}}$ & $23 \pm 5^{\mathrm{B}}$ & $4 \pm 2$ \\
\hline \multirow[t]{4}{*}{ CHX } & 44 & 101 & $8^{\mathrm{bc}}$ & 37 & 63 & 0 \\
\hline & 50 & 136 & $36^{\mathrm{b}}$ & 44 & 56 & 0 \\
\hline & 60 & 147 & $81^{\mathrm{a}}$ & 22 & 76 & 3 \\
\hline & Overall mean & & $41 \pm 11^{\mathrm{C}}$ & $34 \pm 7^{\mathrm{B}}$ & $65 \pm 6^{\mathrm{A}}$ & $1 \pm 1$ \\
\hline \multirow[t]{4}{*}{ DMAP } & 44 & 69 & 65 & 34 & 66 & 0 \\
\hline & 50 & 73 & 84 & 16 & 84 & 0 \\
\hline & 60 & 73 & 100 & 4 & 96 & 0 \\
\hline & Overall mean & & $83 \pm 7^{B}$ & $18 \pm 8^{\mathrm{B}}$ & $82 \pm 8^{A}$ & 0 \\
\hline
\end{tabular}

Means from three replicates. *, EP, electric pulses; ETOH, ethanol; CaA, calcium ionophore; CHX, cycloheximide; DMAP, 6-dimethylaminopurin. **, PN, pronuclear stage; PN-Frag, fragmented eggs

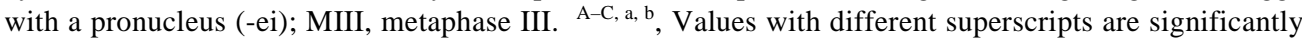
different among treatment $(\mathrm{P}<0.01$ among $\mathrm{A}-\mathrm{C})$ or within treatment $(\mathrm{P}<0.05$ between a and $\mathrm{b}, \mathrm{P}<0.01$ between a and $\mathrm{c}$ ).

Table 2. Types of pronuclear formation of pig eggs activated by different stimuli

\begin{tabular}{|c|c|c|c|c|c|c|c|}
\hline \multirow{3}{*}{ Treatment* } & \multirow{3}{*}{$\begin{array}{c}\text { No. of } \\
\text { oocytes } \\
\text { activated }\end{array}$} & \multicolumn{6}{|c|}{ Percentage of the oocytes showing** } \\
\hline & & \multicolumn{4}{|c|}{ Pronuclear formation } & \multirow[b]{2}{*}{ MIII } & \multirow[b]{2}{*}{ Others $* * *$} \\
\hline & & $1 \mathrm{PN}+\mathrm{PBII}$ & $1 \mathrm{PN}$ & $2 \mathrm{PN}$ & $\geq 3 \mathrm{PN}$ & & \\
\hline EP & 192 & $64 \pm 4^{\mathrm{A}}$ & $9 \pm 2^{\mathrm{B}}$ & $15 \pm 4^{\mathrm{B}}$ & $7 \pm 1$ & $1 \pm 1$ & $5 \pm 2$ \\
\hline ETOH & 132 & $50 \pm 8^{\mathrm{AB}}$ & $13 \pm 2^{\mathrm{B}}$ & $19 \pm 6^{\mathrm{B}}$ & $11 \pm 6^{\mathrm{a}}$ & $8 \pm 5$ & - \\
\hline $\mathrm{CaA}$ & 224 & $59 \pm 6^{\mathrm{AB}}$ & $18 \pm 5^{\mathrm{B}}$ & $7 \pm 2^{\mathrm{B}}$ & $12 \pm 3^{\mathrm{A}}$ & $4 \pm 2$ & - \\
\hline $\mathrm{CHX}$ & 172 & $35 \pm 9^{\mathrm{B}}$ & $14 \pm 5^{\mathrm{B}}$ & $47 \pm 7^{\mathrm{A}}$ & $2 \pm 1^{\mathrm{b}}$ & $1 \pm 2$ & - \\
\hline DMAP & 177 & $3 \pm 2^{\mathrm{C}}$ & $89 \pm 2^{\mathrm{A}}$ & $7 \pm 1^{\mathrm{B}}$ & $1 \pm 1^{\mathrm{Bb}}$ & 0 & - \\
\hline
\end{tabular}

Means from three replicates. *, See footnote to Table 1. **, PN, pronucleus(-ei); +PBII, with the second polar body; MIII, metaphase III. ***, Oocytes having PBI chromatin after electrofusion. A-C, a, b, Figures with different superscripts are significantly different $(\mathrm{P}<0.01$ among $\mathrm{A}-\mathrm{C}, \mathrm{P}<0.05$ between a and $\mathrm{b})$.

the DMAP group displayed one pronucleus and PBI, while the significantly highest incidence of oocytes having two pronuclei and $\mathrm{PBI}$ was noted in the $\mathrm{CHX}$ group (47\%). A limited number of the treated oocytes (1-8\%), except for the DMAP-treatment group, manifested partial activation with the release of PBII, but the remaining chromosomes arrested at the metaphase stage, which is known as the MIII stage. In
$5 \%$ of electrostimulated oocytes, cell fusion occurred between the oocyte and the PBI, and was observed as an "extra" nuclear-like structure in the ooplasm as reported previously [20].

\section{Pronuclear migration and cytoskeletal distribution}

Figs. 1a-g show representative pictures of pronuclear oocytes after different stimuli. Patterns of the 
cytoskeletal distribution are summarized in Table 3. Pronuclear location was assessed with focusing. It was easily identified in relation to the focus plane of the PB's chromatin. In about half of oocytes treated with EP, ethanol and $\mathrm{CaA}(52,46$ and $45 \%$, respectively), the pronucleus had already migrated into the center of the ooplasm (Figs. 1a-c), where the microtubule network was concentrated $(82,45$ and $67 \%$ for corresponding groups, respectively, Table 3 ). In these oocytes, the microtubule and microfilament networks synchronously developed to form each domain, supporting concentrically the pronucleus. However, a very limited number of $\mathrm{CHX}$ - and DMAP-treated oocytes (4 and $8 \%$, respectively) showed pronucleus migration into the center ooplasm (Table 3). In these oocytes, the pronucleus was nearly always located in the peripheral ooplasm even at 12 hrs after initiation of activation. Further, development of the microfilament domain was not synchronous with development of the microtubule network (Fig. 1f). In CHX-treated oocytes, large cytoplasmic microtubule asters were frequently observed, which are referred to as "partially-thickened" in Table 3 (Fig. 1d). A similar feature was occasionally noted in DMAP-treated oocytes. In addition, the oocytes displaying several aggregations of the microtubule-rich domain (referred to as "domaindivided" in Table 3) were found to be the predominant pattern in the DMAP groups (Fig. 1f). Centration of the microfilament domain occurred at higher incidences in the oocytes treated with $\mathrm{EP}, \mathrm{CaA}$ and $\mathrm{CHX}$ (57, 69 and $59 \%$, respectively) than in those treated with ethanol and DMAP (36 and 29\%, respectively). In the latter treatment groups, the oocytes showing separated aggregates of microfilaments of various sizes were more frequently formed than in the other groups (Table 3 ). Some granulated spots of microfilament staining were typically noted in the oocytes after EP and DMAP treatments (referred to as "partially-granulated" in Table 3, photo not shown). Fragmented parthenogenotes, frequently noted in $\mathrm{CHX}$ - and DMAP-treated oocytes, were characterized by divided microtubule domains and remarkably diminished microfilament architecture (Figs. 1e, g).

\section{Discussion}

The present study clearly demonstrated that the incidence of activation of pig oocytes was highest with EP among the treatments examined, and that $\mathrm{CaA}$ and DMAP activated the oocytes in relatively higher proportions than ethanol or $\mathrm{CHX}$. Cha et al. [24] found that pig oocytes matured in vitro are less responsive to ethanol or CaA than to EP. Moreover, the activation efficiency seemed to increase in an age-dependent manner when young oocytes were activated in a relatively low proportion, as seen in the oocytes activated with $\mathrm{CaA}$ or $\mathrm{CHX}$ in this study. $\mathrm{CHX}$ alone is less effective on pig oocytes [13,25], but it is very effective in inducing activation in combination with ethanol, CaA or EP [13, 24, 25]. Very similar results were obtained in activated bovine $[18,26]$ and mouse oocytes [27, 28].

The pronucleus usually migrated into the center of the oocytes when treated with EP, ethanol or CaA. In contrast, in most of the oocytes treated with $\mathrm{CHX}$ or DMAP the pronucleus was located adjacent to the PBI or at the peripheral ooplasm relatively far away from the PBI. It is suggested, therefore, that the pronuclear migration may be impaired in eggs that are treated with $\mathrm{CHX}$ or DMAP. In these eggs, microtubules and microfilaments did not form a concentrated domain and were segmented and scattered in the ooplasm.

It has been shown that MAP kinase is essential for the reorganization of microtubules into the metaphase spindle in the frog [29]. Inhibition of MAP kinase by 6DMAP may explain the release of the MII stage, including the disappearance of the metaphase spindle. Nevertheless, thick and radiating microtubule asters were observed in $\mathrm{CHX}$ - and also DMAP-treated oocytes. Although the biological significance of such features is not clear, it is possible that the effects of the inhibitor are resumed after removal of the chemicals from culture media, facilitating microtubule polymerization in the oocyte. The present study revealed that development of the microtubule network was not synchronous with development of the microfilament domain even at 6 to $8 \mathrm{hrs}$ after release from the effect of inhibitors. It is suggested, therefore, that protein synthesis/phosphorylation inhibitors may affect functional activity in the ooplasm during activation events, including chromosome segregation, polar body emission and pronuclear migration. Treatment of $\mathrm{CHX}$ or DMAP changed the outline of the microvilli on the cell surface of the bovine oocytes [30], suggesting functional changes of the peripheral ooplasm.

Kikuchi et al. [31] have suggested that control of MPF phosphorylation affects somewhat the rates of activation and fragmentation of the pig aged oocytes. The treatment with EP, ethanol or CaA may induce an abrupt increase of $\left[\mathrm{Ca}^{2+}\right]_{\text {i }}$, which is probably linked with inactivation of MPF [8]. While a high percentage of pronuclear formation was achievable after DMAP 

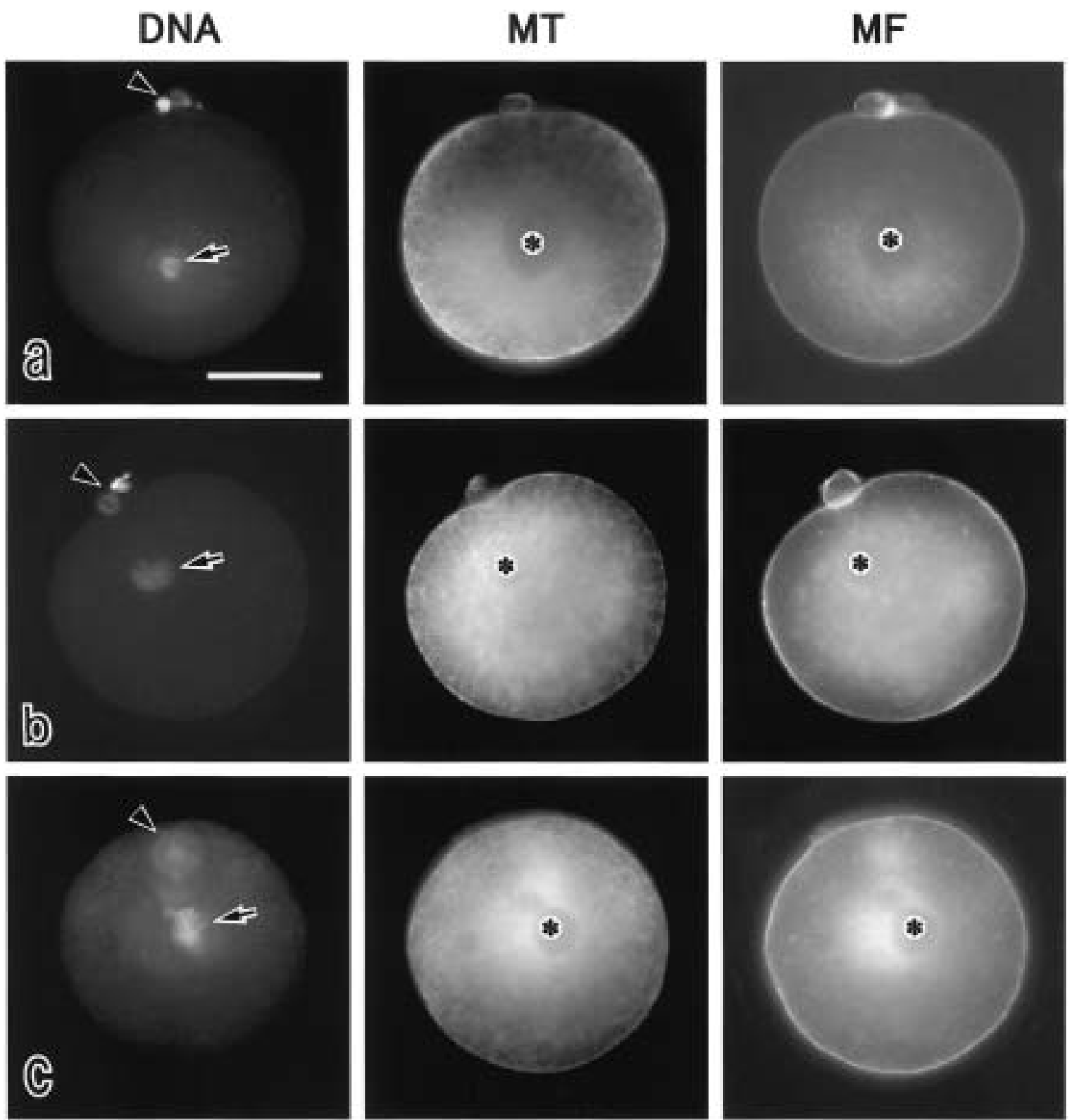

Fig. 1. Pronucleated oocytes stimulated with electric pulses (a), ethanol (b), calcium ionophore (c), cycloheximide (CHX) (d, e) or 6-demethylaminopurin (DMAP) (f, g), triple stained to visualize chromatin (DNA), microtubules (MT) and microfilaments (MF). Bar represents $50 \mu \mathrm{m}$. In the DNA panels, arrowheads show the polar body and arrows show the pronucleus. Asterisks in the MT and MF panels show the location of the pronucleus. a-c) The oocytes activated with stimuli elevating intercellular calcium levels were generally characterized by a well-developed microtubule domain around the pronucleus, which was migrating into the center of the ooplasm. Microfilaments are also concentrated around the pronucleus. d, f) Microtubules and microfilaments are not concentrated at the center of ooplasm after CHX or DMAP treatment. Note segmentation of the cytoskeletal architecture. No migration of the pronucleus occurs in a DMAP-treated oocyte as shown in Fig. 1f, in which the pronucleus is peripherally located near the polar body. e, g) Fragmented oocytes after CHX (e) or DMAP treatment (g) showing fragmentation of the microtubule domain and decreased density of microfilaments in the ooplasm. Note strongly stained microfilaments at the cleavage plane of fragmented blastomeres (small arrows in the MF panel). 

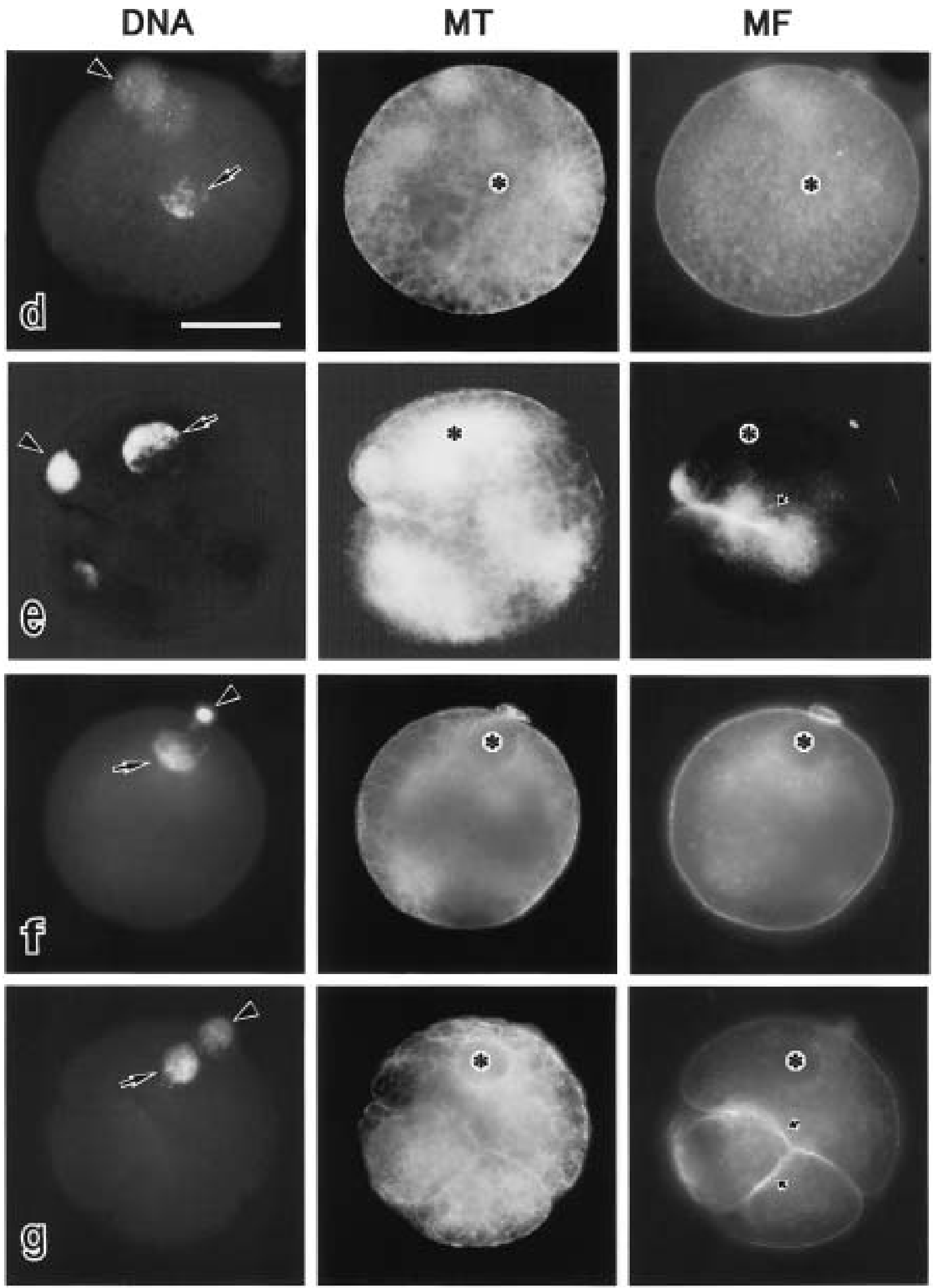
Table 3. Pronuclear centration and cytoskeletal distribution of pig eggs activated by different stimuli*

\begin{tabular}{|c|c|c|c|c|c|c|c|c|}
\hline \multirow[b]{2}{*}{ Treatment* } & \multirow{2}{*}{$\begin{array}{c}\text { No. of } \\
\text { oocytes } \\
\text { evaluated }\end{array}$} & \multirow{2}{*}{$\begin{array}{c}\text { Mean } \% \text { of } \\
\text { oocytes with } \\
\text { PN centration }\end{array}$} & \multicolumn{3}{|c|}{ Microtubules } & \multicolumn{3}{|c|}{ Microfilaments } \\
\hline & & & $\begin{array}{l}\text { Domain- } \\
\text { centrated }\end{array}$ & $\begin{array}{l}\text { Partially } \\
\text { thickened }\end{array}$ & $\begin{array}{l}\text { Domain- } \\
\text { divided }\end{array}$ & $\begin{array}{l}\text { Domain- } \\
\text { centrated }\end{array}$ & $\begin{array}{l}\text { Partially } \\
\text { granulated }\end{array}$ & $\begin{array}{l}\text { Domain- } \\
\text { divided }\end{array}$ \\
\hline EP & 123 & $52 \pm 4^{\mathrm{a}}$ & $82 \pm 6^{\mathrm{A}}$ & 0 & $18 \pm 6^{\mathrm{B}}$ & $57 \pm 7$ & $34 \pm 5^{\mathrm{A}}$ & $9 \pm 3^{\mathrm{Bb}}$ \\
\hline ETOH & 72 & $46 \pm 9^{a}$ & $45 \pm 12^{\mathrm{B}}$ & $17 \pm 10^{\mathrm{B}}$ & $38 \pm 10^{\mathrm{B}}$ & $36 \pm 10^{b}$ & $4 \pm 3^{\mathrm{B}}$ & $59 \pm 11^{\mathrm{Aa}}$ \\
\hline $\mathrm{CaA}$ & 163 & $45 \pm 4^{\mathrm{a}}$ & $67 \pm 9^{\mathrm{AB}}$ & $3 \pm 2^{\mathrm{B}}$ & $30 \pm 9^{\mathrm{B}}$ & $69 \pm 7^{\mathrm{Aa}}$ & $4 \pm 2^{\mathrm{B}}$ & $28 \pm 7^{b}$ \\
\hline $\mathrm{CHX}$ & 50 & $4 \pm 3^{b}$ & $8 \pm 4^{C}$ & $64 \pm 7^{\mathrm{A}}$ & $28 \pm 8^{\mathrm{B}}$ & $59 \pm 12^{\mathrm{a}}$ & $12 \pm 6^{\mathrm{B}}$ & $29 \pm 10^{\mathrm{b}}$ \\
\hline DMAP & 34 & $8 \pm 6^{b}$ & $9 \pm 4^{\mathrm{C}}$ & $17 \pm 7^{\mathrm{B}}$ & $74 \pm 7^{\mathrm{A}}$ & $29 \pm 11^{\mathrm{Bb}}$ & $28 \pm 9^{A}$ & $43 \pm 10^{a}$ \\
\hline
\end{tabular}

*, See text in detail on cytoskeletal distribution. ${ }^{\mathrm{A}-\mathrm{C}, \mathrm{a}, \mathrm{b}}$, Figures with different superscripts within each column are significantly different $(\mathrm{P}<0.01$ among $\mathrm{A}-\mathrm{C}, \mathrm{P}<0.05$ between a and $\mathrm{b})$.

treatment, most of the oocytes fragmented irrespective of the oocyte aging. High incidence of fragmentation was also noted in the $\mathrm{CHX}$-treated oocytes. These observations suggest that some of the DMAP-sensitive kinases may play important role(s) in preventing egg fragmentation.

In conclusion, the activation stimuli elevating $\left[\mathrm{Ca}^{2+}\right]_{i}$ and those inhibiting protein synthesis/phosphorylation exert different effects on the cytoskeletal organization of the oocyte, resulting in different fashions of pronuclear migration and polar body extrusion. Some of the DMAP-sensitive kinases may be involved in the regulation of the polymerization of microtubules and microfilaments for chromosome segregation, polar body emission and pronuclear migration, as well as prevention of egg fragmentation.

\section{Acknowledgements}

The authors thank the staff of the Gene Research Center at Hirosaki University for use of the image analyzing system and the staff of the Inakadate Meat Inspection Office (Aomori, Japan) for supplying pig ovaries.

\section{References}

1) Yanagimachi, R. (1994): Mammalian fertilization. In: The Physiology of Reproduction. (Knobil, E. and Neill, J.D., eds.), pp. 189-317, Ravan Press, New York.

2) Didion, B.A., Martin, M.J. and Markert, C.L. (1990): Parthenogenetic activation of mouse and pig oocytes matured in vitro. Theriogenology, 33, 1165-1175.

3) Funahashi, H., Cantley, T.C., Stumpf, T.T., Terlouw, S.L. and Day, B.N. (1994): In vitro development of in vitromatured porcine oocytes following chemical activation or in vitro fertilization. Biol. Reprod., 50, 1072-1077.

4) Hagen, R.D., Prather, R.S. and First, N.L. (1991): Response of porcine oocytes to electrical and chemical activation during maturation in vitro. Mol Reprod. Dev., $28,70-73$.

5) Prather, R.S., Eichen, P.A., Nicks, D.K. and Peters, M.S. (1991): Artificial activation of porcine oocytes matured in vitro. Mol Reprod. Dev., 28, 405-409.

6) Prochazka, R., Kanka, J., Sutovsky, P., Fulka, J. and Moltik, J. (1992): Development of pronuclei in pig oocytes activated by a single electric pulse. J. Reprod. Fertil., 96, 725-734.

7) Sun, F.Z., Hoyland, J., Huang, X., Mason, W. and Moor, R.M. (1992): A comparison of intracellular changes in porcine eggs after fertilization and electroactivation. Development, 115, 947-956.

8) Masui, Y. and Markert, G.E. (1971): Cytoplasmic control of nuclear behavior during meiotic maturation of frog oocytes. J. Exp. Zool., 177, 129-146.

9) Szollosi, M.S., Kubiak, J.Z., Debey, P., de Pennart, H., Szollosi, D. and Maro, B. (1993): Inhibition of protein kinases by 6 -dimethylaminopurine accelerates the transition to interphase in activated mouse oocytes. J. Cell Sci., 104, 861-872.

10) Moses, R.M. and Masui, Y. (1994): Enhancement of mouse eggs activation by the kinase inhibitor, 6dimethylaminopurine (6-DMAP). J. Exp. Zool., 270, 211218.

11) Susko-Parrish, J.L., Leibfried-Rutledge, M.L., Northey, D.L., Schutzkus, V. and First, N.L. (1994): Inhibition of protein kinases after an induced calcium transient causes transition of bovine oocytes to embryonic cycles without meiotic completion. Dev. Biol., 166, 729-739.

12) Mayers, M.A., Stogsdill, P.L. and Prather, R.S. (1995): Parthenogenetic activation of pig oocytes by protein kinase inhibition. Biol. Reprod., 53, 270-275.

13) Nussbaum, D.J. and Prather, R.S. (1995): Differential effects of protein synthesis inhibitors on porcine oocyte activation. Mol. Reprod. Dev., 41, 70-75.

14) Leal C.L.V. and Liu, L. (1998): Differential effects of kinase inhibitor and electrical stimulus on activation and histone $\mathrm{H} 1$ kinase activity in pig oocytes. Anim. Reprod. Sci., 52, 51-61.

15) Nagai, T. (1987): Parthenogenetic activation of cattle follicular oocytes in vitro with ethanol. Gamete. Res., 16, 
$243-249$.

16) Ware, C.B., Barnes, F.L., Maiki-Laurila, M. and First, N.L. (1989): Age-dependence of bovine oocyte activation. Gamete Res., 22, 265-275.

17) Yang, X., Jiang, S., Farrell, P., Foote, R.H. and McGrath, A.B. (1993): Nuclear transfer in cattle: Effect of nuclear donor cells, cytoplast age, co-culture, and embryo transfer. Mol. Reprod. Dev., 35, 29-36.

18) Presicce, G.A. and Yang, X. (1994): Nuclear dynamics of parthenogenesis of bovine oocytes matured in vitro for 20 and $40 \mathrm{hr}$ and activated with combined ethanol and cycloheximide treatment. Mol. Reprod. Dev., 37, 61-68.

19) Suzuki, H., Liu, L. and Yang, X. (1999): Age-dependent development and surface ultrastructural changes following electrical activation of bovine oocytes. Reprod. Fertil. Dev., 11, 159-165.

20) Suzuki, H., Takashima, Y. and Toyokawa, K. (2002): Cytoskeletal organization of porcine oocytes aged and activated electrically or by sperm. J. Reprod. Dev., 48, 293-301.

21) Suzuki, H., Takashima, Y. and Toyokawa, K. (2002): Parthenogenetic development and cytoskeletal distribution of porcine oocytes treated by electrical pulses and cytochalasin D. J. Mamm. Ova Res., 19, 6-11.

22) Suzuki, H., Jeong, B-S. and Yang, X. (2000): Dynamic changes of cumulus-oocyte cell communication during in vitro maturation of porcine oocytes. Biol. Reprod., 63, 723-729.

23) Suzuki, H., Takashima, Y. and Toyokawa, K. (2001): Influence of incubation temperature on meiotic progression of porcine oocytes matured in vitro. J. Mamm. Ova Res., $18,8-13$.

24) Cha, S.K., Kim, N-K., Lee, S.M., Baik, C.S., Lee, L.T. and
Chung, K.S. (1997): Effect of cytochalasin B and cycloheximide on the activation rate, chromosome constituent and in vitro development of porcine oocytes following parthenogenetic stimulation. Reprod. Fertil. Dev., 9, 441-446.

25) Grocholova, R., Petr, J., Rozinek, J. and Jilek, F. (1997): The protein phosphates inhibitor okadaic acid inhibits exit from metaphase II in parthenogenetically activated pig oocytes. J. Exp. Zool., 277, 49-56.

26) Yang, X., Presicce, G.A., Moraghan, L., Jiang, S.E. and Foote, R.H. (1994): Synergistic effect of ethanol and cycloheximide on activation of freshly matured bovine oocytes. Theriogenology, 41, 395-403.

27) Bos-mikich, A., Swann, K. and Whittingham, D.G. (1995): Calcium oscillations and protein synthesis inhibition synergistically activate mouse oocytes. Mol. Reprod. Dev., 41, 84-90.

28) Hagemann, L.T., Hilleryweinhold, F.L., Rutledge, M.L.L. and First, N.L. (1995): Activation of murine oocytes with $\mathrm{Ca}^{2+}$ ionophore and cycloheximide. J. Exp. Zool., 271, 5761.

29) Gotoh, Y., Moriyama, K., Matsuda, S., Okumura, E., Kishimoto, T., Kawasaki, H., Suzuki, K., Yahara, I., Sakai, H. and Nishida, E. (1991): Xenopus M phase MAP kinase: isolation of its cDNA and activation by MPF. EMBO J., 10, 2661-2668.

30) Suzuki, H., Ju, C-J. and Yang, X. (2000): Surface ultrastructural alterations of bovine oocytes after parthenogenetic activation. Cloning, 2, 69-78.

31) Kikuchi, K., Naito, K., Noguchi, J., Shimada, A., Kaneko, H., Yamashita, M., Aoki, F., Tojo, H. and Toyoda, Y. (2000): Maturation/M-phase promoting factor: A regulator of aging in porcine oocytes. Biol. Reprod., 63, 715-722. 